\title{
Determinants of Team Climate and Team Trust on Team Performance-An Extensive Examination
}

\author{
Rajeesh Viswanathan, Divya Lakshmi, Jahira Parveen
}

\begin{abstract}
Purpose: Team Climate is foreseen as a variable that enhances the organizations effectiveness, if the criterion has been satisfied under particular working conditions. It is said that team climate can be viewed under perceptions that are shared under a proximal working team. The study focuses on the conceptual framework of Team climate that enhances the organizations effectiveness what are the predictors to be thrown limelight to improve the same.
\end{abstract}

Team climate and Leadership has been viewed as implicitly inter-related variables as a warm conducive work climate would lead to an effective leadership quality which also extensively affects the two prime attributes such as knowledge-sharing and innovative Work behavior of an employee.

Design / Methodology/Approach: The focus of this study is to assess the determinants of theTeam Climate on Work Teams. The data for the study was collected from the software developers from various IT organizations. The team climate inventory (TCI) used in the study also has to tested for its impact on the Work Teams.

The sample data was obtained from five major IT organizations in Chennai and Bangalore region. Selected organizations mainly comprises of the Software Developer's Team under the Self Managed Team base. The data used for the study is empirical though some of the base studies was found to contain information form appropriate sources. The basic tools used for analysing the data were IBM SPSS Statistics20 and multiple regressions were performed using AMOS Graphics for running the Structured Equation Modeling Technique (SEM).

Scale development: The Team Climate Inventory(TCI) which uses the five point Agreement scale contains four dimensions namely Vision(12),Task Orientation(7), Support for Innovation (8) Participative Safety (7) which accounts to nearly 34 items. The scale was developed by Neil.R.Anderson and Michael A.West (1994).

Findings and Implications: The research findings about the study done on the determinants of team climate shows that the factor loadings pertaining to the Confirmatory Factor Analysis (CFA) using AMOS Graphics (SEM) has been proved to be have a good impact and thereby it is to be implied that there prevails a conducive team climate in the organization which serves as a limelight for a best level of Knowledge sharing behaviour and Innovative work behaviour among employees in the organization.

Conclusion: Thus it has been found from the research findings and observations that a good Team climate among the work teams would enhance the Team Trust as observed from the meta analytical studies, that in turn would boost the Knowledge sharing and the Innovative Work Behaviour amongst Teams to a greater appreciable level.

Revised Manuscript Received on July 05, 2019

Dr. Rajeesh Viswanathan, Assistant Professor, Dept of International Business, School of Management, Pondicherry University, Pondicherry.

Divya Lakshmi, Research Scholar, Dept of International Business, School of Management, Pondicherry University, Pondicherry, India.

Dr. Jahira Parveen, Assistant Professor, Faculty of Management, SRM Institute of Technology, Chennai, India.
Scope: The study involves only on IT sector, whereas the study can be examined in different sectors, like manufacturing, hospitality and tourism sector.

Index Terms: Authentic Leadership, Team Climate, Innovative Work Behaviour, Self-managed teams, Trust.

\section{INTRODUCTION}

Team Climate is foreseen as a variable that enhances the organizations effectiveness, if the criterion has been satisfied under particular working conditions. It is said that team climate can be viewed under perceptions that are shared under a proximal working team. The expert team has developed the team climate inventory keeping in mind the scope for its innovative behavior. The factors under study for Team Climate would be classified as Vision, Participative Safety, Task Orientation and Support for Innovation (West, 1990, in Anderson and West, 1998, p. 240). The study focuses on the conceptual framework of Team climate that enhances the organizations effectiveness what are the predictors to be thrown limelight to improve the same.

Team climate and Leadership has been viewed as implicitly inter-related variables as a warm conducive work climate would lead to an effective leadership quality which also extensively affects the two prime attributes such as knowledge-sharing and innovative Work behavior of an employee. Team Climate is been perceived as a factor that possess a quality of shaping an employee's attitude, behavior and perception.

\section{REVIEW OF LITERATURE}

\subsection{Team Climate on Innovative Work Behavior (IWB)}

Their designations comprises of Team Analyst, Team Lead, Project Manager, Senior Project Manager, Group Project Manager, Development Manager, Senior Development Management Caroline Burningham and Michael A. West in their Small Group research have done an extensive study on the role played by an individual innovativeness and Team Climate factors on Innovativeness in Work Groups. The study was conducted in an Oil company comprising of 59 members in a group of 13 teams. Caroline Burningham and Michael A. West in order to find the range of work team innovation relies on the four factors of the Team Climate inventory namely Team Vision, Participative Safety, Task Orientation and Support for Innovation. The findings from the research study shows that the ratings obtained from the predictors of Team Climate and Group Innovation

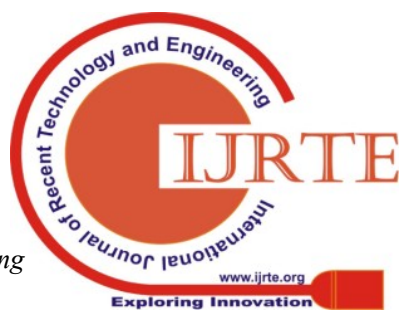


processes were externally related to the measures of Group Innovativeness. Research observations also say that the Support for innovation module from the Team Climate Inventory(TCI) has been noted to be the most consistent module and all the four dimensions of TCI are all significantly correlated with the innovativeness quotient and hence also delivers an eminent support to the theoretical predictors as well.

Neil Anderson \& Michael A. West in their study Development of Team Climate Inventory (TCI) and its application in Team building for innovativeness describes about the application and development of TCI and also the functions involved in a group in order to validate its contribution involved in Team building and thereby its impact on Team innovation. The researchers have done two case studies for diagnosing the developed TCI. The researchers have included the work and organization $(\mathrm{W} / \mathrm{O})$ psychologists and personnel practitioners in the study. They are made to be more focused upon their competence in existence and also the measurement skills concerned with individual assessments. The cases involved in the study deals with the phenomena in organizations based upon the three suppositions namely the international changes in the business environment, the new practices in organizations have promoted more of Team working within the employees and the $\mathrm{W} / \mathrm{O}$ practitioners are not on par with the these trends and hence fail to meet the demands of the HR practitioners. The researchers have concluded by saying that the W/O psychologists have shown active participation in the team and also had involved themselves into enhancement of team innovativeness.

\subsection{Team Climate on Knowledge Sharing Behaviour(KS)}

Yajiong Xue, John Bradley and Huigang Liang Assistant Professor, in the College of Business,East Carolina University,Greenville, North Carolina,USA have done a research to investigate the impact of Team Climate and Empowering Leadership on knowledge sharing behavior . They have developed a research model pertaining to knowledge management studies and partial least square method was used to test the developed model. The findings show that the two constructs tends to have positive impact on the knowledge sharing behavior. The practical implications of this research is to design teams that facilitate knowledge sharing, they also observed that knowledge sharing is at its best level when the teams exhibit cohesive and innovative group behavior under existence of trust in work teams.

\subsection{Team Climate on Team Performance}

Henrik Bresman,Fontainebleau Cedex, In their study, External Learning Activities and Team Performance: A Multimethod Field Study, have focused upon the two major variables involving external learning activities that influence the team's performance. The study differentiates the connection between the two external learning activities the method which is employ to make the teams effective. The two types of learning namely the vicarious learning which is based on similar experiences and contextual learning based on the sources inclined with the context. The author also has foreseen the study by associating the vicarious learning team involving in internal activities and thereby validating the team's performance when indulged in these internal activities.
The study also proposes to develop a model to assess the impact of external activities on the team's performance.

Susan Mohammed, Sucheta Nadkarni, Temporal Diversity and Team Performance: The moderating effect of Team Temporal Leadership is based on components of Team Temporal Diversity with dimensions such as Urgency, Pacing Style and Time perspective on Team Performance. The data is collected from business process firms that deal with outsourcing activities that consists of 71 in number. The findings portray that the temporal leadership acts as a moderator to test the relationship between Time urgency and Team performance and also to test the relationship pacing style of temporal diversity on Team Performance. Team Temporal Leadership has a positive impact on Team Performance. The Temporal Leadership is estimated on the basis of how the Teams respond to constraints such as scheduled deadlines; synchronize team member behaviors and Allocation of temporal resources. Results have specified that the temporal individual differences and their significant relationship with Team Performance that clearly prescribes the temporal diversity constraints under which the Team's performance can be maximized.

Chieh-Peng Lin, Yehuda Baruch, Wei-Chi S, In their research Corporate Social Responsibility and Team Performance: The Mediating Role of Team Efficacy and Team Self-Esteem, The corporate social responsibility otherwise called corporate citizenship with its three dimensions namely the Economic citizenship, Legal citizenship and Ethical citizenship has been tested for its influence on Team Performance. The mediators used in the study are Team Efficacy and Team Self Esteem.

The research team has carried out survey amongst 172 teams. Findings puts forth the role played by the mediation on the three dimensions of corporate social responsibility wherein economic citizenship has an influence on Team Performance indirectly, Team efficacy alone has an impact on Team performance through Legal Citizenship and Ethical citizenship has an effect on Team Performance while in mediation with only self esteem and there is no significant impact when Team efficacy medium is taken into consideration. The implications of the study mainly discussed in the context of theoretical and managerial perspectives. The Team's efficacy used for mediation can be considered the courage possessed by self or an individual's confidence level in order to perform a designated task. Self efficacy another mediation variable in the study has an in built concept namely the self-esteem or the self id or ego and the evaluation based on self which talks about motivation within self and overall estimation of the self values and adherence and discharge of duties with the at most targeted performance.

J. Alberto Espinosa, Sandra A. ,Robert E. Kraut, James D. in their study Familiarity, Complexity, and Team Performance in Geographically Distributed Software Development deals with the two major types of familiarity namely the Team familiarity and Task familiarity. The types of familiarity impact depends upon the complexity associated in work. The interaction with task with Team familiarity and Task co-ordination to its complexity has an effect on Team Performance. It has been observed that task familiarity is more prone to heavier tasks. Team familiarity seems to be 
tough when the there is less team coordination. The impact of Task and Team familiarity are said to complement each other for instance we take the respondents those are distributed in various locations where in teams from the software domain has been considered.The impact of Task familiarity seems to decline when tasks are very tough or harder to accomplish and not dependent upon the task size. The results have confirmed that the effect of team familiarity is more when the coordination in Teams is complex that is when the teams are big in size or dispersed in dimensions of varied locations, Task and Team Familiarity seems to be more effective on Team Performance and complements one to one.

\subsection{Team Trust in work teams}

Mila Hakanen and Aki Soudunsaari in his research study Building Trust in High -Performing Teams defines trust as a facilitator for development for a company rather than its capital investment for business activities and trust serves as one of the important factors that aid growth in teams. Co-ordination in teams, transparency and open discussions within teams also helps teams to become self motivated and work towards their common goals and achievements. Communication is yet another factor which boosts up performance in Teams, because one to one communication improves concern and understands state of mind of peer group that serves as an entity to build trust in order to equip them to teams of high performing standards.

In a study conducted by Porter, Indiana University et al on The Effects Of Conflict, Trust, And Task Commitment On Project Team Performance based upon strategic teams that deals with testing a conceptual model upon student teams that are nearly forty in number engaged in for a project work involving case study for a product that is to be launched. The researchers have developed a model for the performance in teams ,the variables focused upon in the model would be commitment to task that was found to possess an indirect relationship with team performance and Trust in Teams which was also observed to possess an indirect relationship with Team's Performance. The predominant variables that have been found to exhibit a direct effect would be conflict that mainly deals with the intra team conflict and Task, kind of process work associated with it. The findings thus was supported an empirically tested by the researchers.

\subsection{Samples and Procedures}

The main aim of this study is to assess the determinants of Team Climate on Work Teams. The data for the study was collected from the software developers from various IT organizations. The team climate inventory (TCI) used in the study also has to tested for its impact on the Work Teams.

The sample data was obtained from five major IT organizations in Chennai and Bangalore region. Selected organizations mainly comprises of the Software Developer's Team under the Self Managed Team base. These employees mainly come under the first and the second tier that is the Development head and the managerial level software project developers. They sample population is nearly 35000 to 40000 employees per organization. Manager, Development Head, Senior Development Head, Promotion Head.

The data used for the study is empirical though some of the base studies was found to contain information form appropriate sources. The basic tools used for analysing the data were IBM SPSS Statistics20 and multiple regressions were performed using AMOS Graphics for running the Structured Equation Modeling Technique (SEM).The data samples were collected from the first five top rated IT companies as per the NASCOM (2017) report.

\subsection{Scale development}

The Team Climate Inventory(TCI) which uses the five point Agreement scale contains four dimensions namely Vision(12),Task Orientation(7), Support for Innovation(8) and Participative Safety(7) which accounts to nearly 34 items. The scale was developed by Neil.R.Anderson and Michael A.West (1994). The Team Trust variables has four predictors namely Team Benevolence(4),Team Identity(4),Team Predictability(4) and has been developed by Cook \& Wall, 1980; Costa, Roe, \& Thaillieu, 2001; Cummings \& Bromiley, 1996; Dirks, 1999; Simons \& Peterson, 2000 .The Team Performance scale has three major dimensions namely Efficiency (7),Effectiveness(8) and Time Awareness(TA), developed by Ancona \& Caldwell, 1992, Edmondson's (1996). 

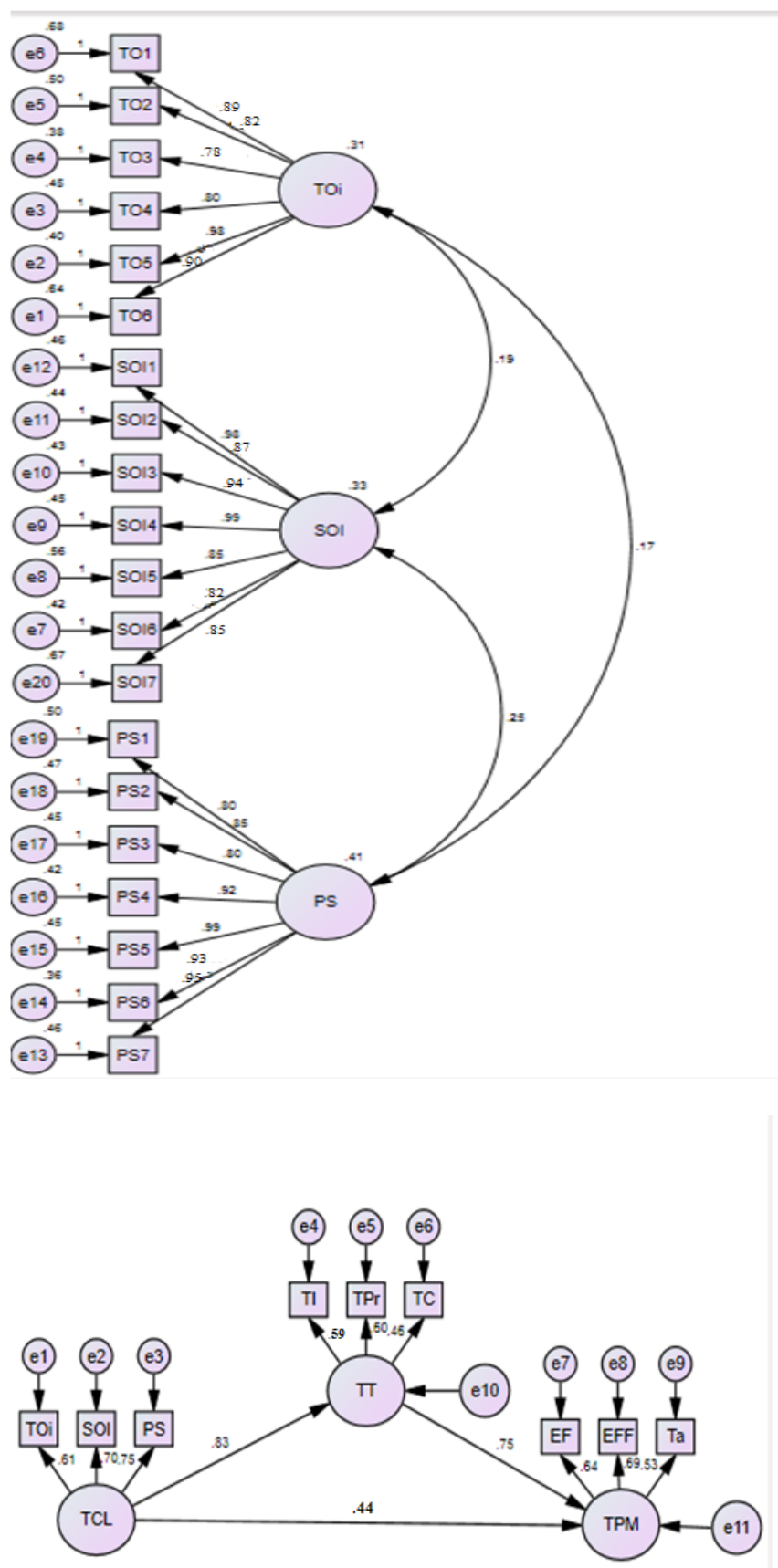

\section{FINDINGS AND IMPLICATIONS}

The research findings about the study done on the determinants of team climate shows that the factor loadings pertaining to the Confirmatory Factor Analysis (CFA) using AMOS Graphics (SEM) has been proved to be have a good impact and thereby it is to be implied that there prevails a conducive team climate in the organization which serves as a limelight for a best level of Knowledge sharing behaviour and Innovative work behaviour among employees in the organization.

\subsection{Team Climate (TCL) and Team Performance (TP)}

The Team Climate (TCL) in the model involves constructs that creates a clear vision that promotes task orientation amongst the team and enhances support that paves path for the employees to be innovative and increases the participative safety .The performance in work teams would surely be in higher levels and hence the climatic constituents in a team would rather aid the dimensions of performance of the work teams to a higher standard.

\subsection{Team Trust (TT) A Positive Mediator}

Team Trust (TT) has been as been introduced as a mediator in the model and the dimension of Team Trust has been associated with Team climate in a positive way and the theoretical background for the variable is hence been proved .The Team Performance is found to be increasing involving the Team Trust through the model and the study hence has the base model support for Self managed teams in a supportive Team Climate and Thereby the performance in the teams tends beat up its bench marks as it has a remarkable orientation under a supportive leadership style which may also contribute to the model acceptance.

\section{CONCLUSION}

Thus it has been found from the research findings and observations that a good Team climate among the work teams would enhance the Team Trust as observed from the meta analytical studies, that in turn would boost the Knowledge sharing and the Innovative Work Behaviour amongst Teams to a greater appreciable level.

\section{REFERENCES}

[1] Anderson, N. R., \& West, M. A., Measuring climate for work group innovation: development and validation of the team climate inventory. Journal of organizational behavior, 235-258 (1998).

[2] Bain, P. G., Mann, L., \& Pirola-Merlo, A., The innovation imperative: The relationships between team climate, innovation, and performance in research and development teams. Small group research, 32(1), 55-73 (2001).

[3] Bower, P., Campbell, S., Bojke, C., \&Sibbald, B., Team structure, team climate and the quality of care in primary care: an observational study. BMJ Quality \& Safety, 12(4), 273-279 (2003).

[4] Burningham, C., \& West, M. A., Individual, climate, and group interaction processes as predictors of work team innovation. Small group research, 26(1), 106-117 (1995).

[5] Černe, M., Jaklič, M., \& Škerlavaj, M., Authentic leadership, creativity, and innovation: A multilevel perspective. Leadership, 9(1), 63-85, 2013.

[6] Dackert, I., Lööv, L. Å., \& Mårtensson, M., Leadership and climate for innovation in teams. Economic and Industrial Democracy, 25(2), 301-318 (2004).

[7] Herman, H. M., Dasborough, M. T., \&Ashkanasy, N. M., A multi-level analysis of team climate and interpersonal exchange relationships at work. The Leadership Quarterly, 19(2), 195-211 (2008).

[8] Pirola-Merlo, A., Härtel, C., Mann, L., \& Hirst, G., How leader influence the impact of affective events on team climate and performance in R\&D teams. The leadership quarterly, 13(5), 561-581 (2002).

[9] Pirola-Merlo, A., Härtel, C., Mann, L., \& Hirst, G., How leaders influence the impact of affective events on team climate and performance in R\&D teams. The leadership quarterly, 13(5), 561-581 (2002).

[10] Xue, Y., Bradley, J., \& Liang, H., Team climate, empowering leadership, and knowledge sharing. Journal of knowledge management, 15(2), 299-312 (2011). 